\title{
Synthesis of Dual Orexin Receptor Antagonist MK-6096
}
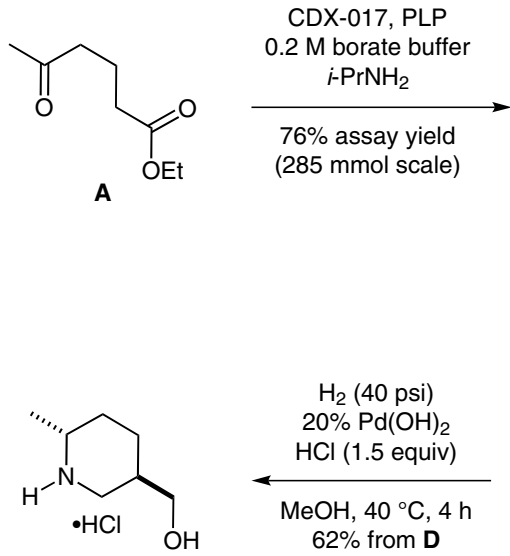<smiles>CC1CCCC(=O)N1</smiles>

B

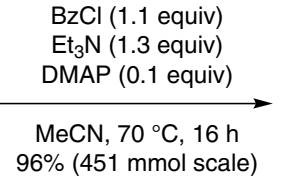

$96 \%$ (451 mmol scale)

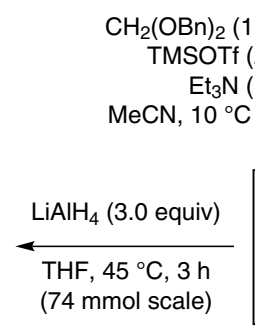<smiles>C[C@@H]1CCCC(=O)N1C(=O)c1ccccc1</smiles>

mp not reported $>99 \%$ ee<smiles>[R]N1C[C@H](COCc2ccccn2)CC[C@H]1C</smiles>

$\mathbf{E}(\mathrm{R}=\mathrm{Bn})+\mathbf{F}(\mathrm{R}=\mathrm{H})$
Gategory

Synthesis of Natural

Products and

Potential Drugs

\section{Key words}

MK-6096

orexin antagonists

amide bond

formation

1-propylphosphonic anhydride

enzymatic transamination

Mukaiyama directed aldol reaction

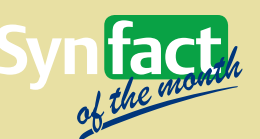

mp not reported

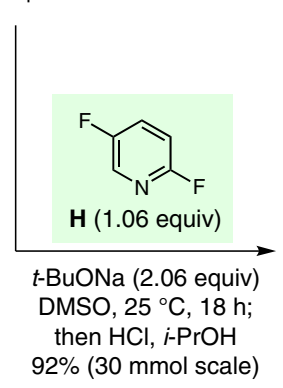

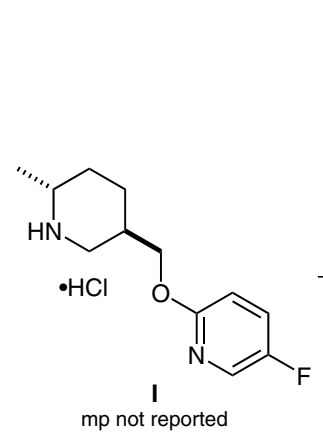

trans $/$ cis $=99.6: 0.4$

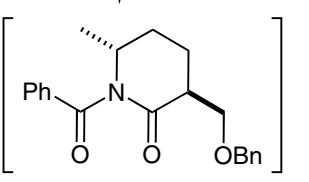

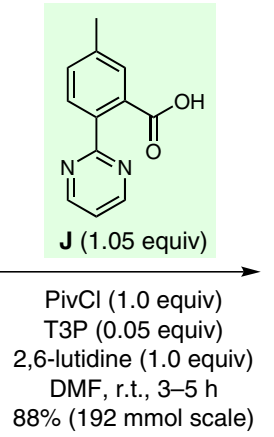

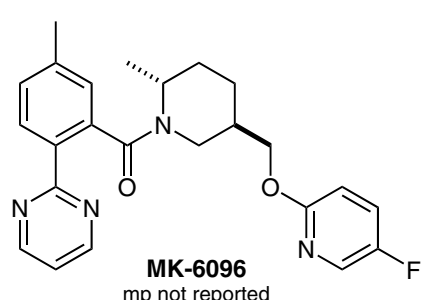

Significance: Orexins-A and -B are neuropeptides that regulate arousal and sleep-wake cycles by hypothalamic signaling through the orexin-1 and -2 receptors. MK-6096 is a dual orexin receptor antagonist that is of interest for the treatment of insomnia. In the asymmetric synthesis depicted (7 steps, 37\% overall), the key stereogenic steps are (1) a biocatalytic transamination $(\mathbf{A} \rightarrow \mathbf{B})$ and (2) a highly diastereoselective Mukaiyama directed aldol reaction $(\mathbf{C} \rightarrow \mathbf{D}, \mathrm{dr}>$ 99:1).
Comment: During a previous kg-scale synthesis of MK-6096 (M. Girardin et al. Org. Process Res. Dev. 2013, 17, 61) the challenging amidation of fragments $\mathbf{I}$ and $\mathbf{J}$ required 3.4 equivalents of expensive T3P (1-propylphosphonic anhydride). In the current route the same amidation was accomplished using only 0.05 equivalents of T3P together with stoichiometric amounts of pivaloyl choride as the dehydrating agent. A mechanism for this unusual transformation is presented that implicates participation by the pyrimidine ring. 